\title{
The Relationship of Mandibular Third Molars with Inferior Alveolar Nerve Based on Orthopantomogram
}

\author{
Muhammad Ikram Khan', Omer Sefvan Janjua ${ }^{2}$, Muhammad Hammad ${ }^{3,}$, ,iaz Ahmad Warraich \\ ${ }^{1}$ Oral and Maxillofacial Surgery, King Edward Medical University, Lahore, Pakistan \\ ${ }^{2}$ Department of Oral and Maxillofacial Surgery, Allied Hospital, Faisalabad, Pakistan \\ 3Oral and Maxillofacial Surgery, Allied Hospital, Faisalabad, Pakistan \\ ${ }^{4}$ Department of Oral and Maxillofacial Surgery CMH, Medical and Dental College, Lahore, Pakistan \\ Email address: \\ malikhammad301@gmail.com (M. Hammad) \\ *Corresponding author
}

\section{To cite this article:}

Muhammad Ikram Khan, Omer Sefvan Janjua, Muhammad Hammad, Riaz Ahmad Warraich. The Relationship of Mandibular Third Molars with Inferior Alveolar Nerve Based on Orthopantomogram. International Journal of Clinical Oral and Maxillofacial Surgery.

Vol. 6, No. 2, 2020, pp. 56-59. doi: 10.11648/j.ijcoms.20200602.17

Received: November 17, 2020; Accepted: November 30, 2020; Published: December 8, 2020

\begin{abstract}
Introduction: A tooth that is unable to erupt completely due to some physiological barrier is called impaction. The extraction of the impacted mandibular $3^{\text {rd }}$ molar is the most frequent procedure in oral surgery. The removal of $3^{\text {rd }}$ molar is associated with complications like damage to the inferior alveolar nerve which causes paresthesia of the lower lip depending upon the severity of the damage. Objectives: This study assesses the diagnostic efficacy of orthopantomograph in predicting the association between mandibular third molar roots and inferior alveolar canal and its juxtaposition with intra-operative surgical findings. Material and methods: This cross-sectional research was conducted in the department of Oral \& Maxillofacial Surgery, King Edward Medical University/Mayo Hospital, Lahore, requiring extraction of mandibular third molars surgically. Patients underwent extraction under local anesthesia. The association between M3 and IAC by comparing OPG findings with intra-operative surgical findings was assessed by chi-square analysis. Results: One hundred and twenty patients requiring mandibular third molar extraction were included in the study. The age of the patients involved in the study ranged from 21-70 years. There were 5 cases of nerve injury in the age group of 31-40 and 1 case in each age group of 21-30 and 41-50. Conclusion: The chances of nerve damage also increase significantly when there is more than one radiographic sign present and the tooth is deeply placed in the mandible nearest to the IAN.
\end{abstract}

Keywords: Impaction, Inferior Alveolar Nerve, Neurosensory Dysfunction, Orthopantomograph

\section{Introduction}

A tooth that is unable to erupt and come into a functional position due to some physiological barrier either entirely or partially. The barrier may be either another tooth, bone, soft tissue, or different type of pathologies among which pericoronitis is the most common. The extraction of impacted mandibular third molar (M3) is one of the most frequent procedures in oral surgery. Neurosensory dysfunction of iatrogenic origin is the most distressing sequel to this procedure [1]. The incidence of this complication ranges from $0.5 \%$ to $5.3 \%$, third most common after alveolar osteitis and post-operative infections [10].
The inferior alveolar nerve (IAN) is the most frequently injured (64.4\%), followed by the lingual nerve (LN) $(28.8 \%)$. The resultant modified sensation or anesthesia of the lower lip is an unsavory condition, and not withstanding its mental outcomes, it is turning into a typical reason for case. [2]. Manual as well as mechanical instruments utilized in the closeness of fragile structures (vascular, sensory tissue) don't permit control of the cutting profundity and can harm these sensitive structures by unintentional contact [3, 4]. The inferior alveolar nerve goes inside the alveolar trench (IAC) in the mandible and is along these lines upheld by the alveolus and the neurovascular group in an arrangement that most superiorly vein followed by artery and afterward IAN. 
During extraction bleeding from the socket suggest that there is damage to the vein and the superior aspect of the bony canal has been exposed.

As there is high variability in the IAN-third molar relationship, a detailed pre-employable radiographic evaluation is needed to recognize both the position (buccal, lingual, or inferior) and guess of the inferior alveolar canal to the third molar to limit the danger of postoperative dysaesthesia. To evaluate the difficulty level of third molar surgery, both clinical and radiographic findings must be taken into account which not only helps to correctly plan the operation but also increase patient satisfaction level [8]. Although the risk of nerve injury can be reduced with careful surgical technique, it cannot be absolutely avoided [9].

The close proximity of the inferior alveolar nerve to the roots of the impacted mandibular third molar is well known. Therefore, the injury to the inferior alveolar and the lingual nerve is characteristic complications following the removal of the impacted lower third molar. The reported incidence of the inferior alveolar nerve injury after the surgical removal of impacted lower third molar ranges from $0.4 \%$ to $8.4 \%$ [6]. A nearby anatomic connection between the roots of the third molar and the mandibular canal puts the inferior alveolar nerve in danger of harm. Among radiographs, orthopantomogram (OPG) is recommended as the primary investigation of choice [5]; other techniques include intraoral radiographs, cross-sectional tomographs, scanographs, volumetric computed tomography (VCTs), and computed tomography (CTs) [7].

This study assesses the diagnostic efficacy of orthopantomograph in predicting the relationship between mandibular third molar roots and inferior alveolar canal and its association with intra-operative surgical findings. This assessment will provide guidance to the surgeon to avoid the complication of inferior alveolar nerve injury and help identify cases that need further sophisticated investigative techniques like computed tomographs and volumetric computed tomography.

\section{Methodology}

After ERC endorsement, this cross-sectional study was led in the department of Oral and Maxillofacial Surgery, King Edward Medical University/Mayo Hospital, Lahore, requiring careful extraction of mandibular third molars. The non-probability, purposive sampling technique was used. Preoperative panoramic and intraoral periapical radiographs were taken. One molar was extricated in each surgical procedure. Patients underwent extraction under local anesthesia. Only those patients who were between age 21-70 years, irrespective of genders presented with complaints of swelling, pain, pericoronitis, trismus, and grossly carious teeth were included in the study. The patients with systemic disease and co-morbid conditions were not included in the study. The data was analyzed using spss version 10.0. frequency distribution of qualitative variables such as gender was determined. The mean and standard deviation was also determined. the $\mathrm{p}$-value of $\leq 0.05$ was considered significant. The association between M3 and IAC by comparing OPG findings with intra-operative surgical findings was assessed by chi-square analysis.

\section{Results}

One hundred and twenty patients requiring the mandibular third molar extraction was included in the study. Preoperative panoramic radiograph was taken. The age of the patients involved in the study ranged from 21-70 years. The number of patients in the age range $21-30$ years was 61 (50.83\% of cases), 31-40 years was 29 (24.17\% of cases), $41-50$ years was 17 (14.17\% of the cases), $51-60$ years was $9(7.5 \%$ of the cases) and $61-70$ years was 4 (33.33\% of the cases). There were 5 cases of nerve injury in the age group of 31-40 and 1 case in each age group of 21-30 and 41-50.

Of the hundred and twenty patients, 58 (48.33\%) were male and $62(51.67 \%)$ were female patients. Inferior alveolar nerve damage was seen in 6 males $(85.71 \%)$ and 1 female (14.29\%) patient. Mesioangular impactions were seen in 71 $(63 \%)$ of cases, Distoangular impactions were seen in 13 $(10.83 \%)$ of cases, Horizontal impactions were seen in 15 $(12.5 \%)$ of cases, Vertical impactions were seen in $21(17.5 \%)$ of cases as mentioned in Table 1.

Table 1. Angulation of the tooth.

\begin{tabular}{lllll}
\hline & & $\begin{array}{l}\text { \% age of } \\
\text { Angulations }\end{array}$ & $\begin{array}{l}\text { No Nerve } \\
\text { Injury }\end{array}$ & $\begin{array}{l}\text { Nerve } \\
\text { Injury }\end{array}$ \\
\hline Angulation & $\mathrm{N}=120$ & $\mathrm{~N}=120(100 \%)$ & $\mathrm{N}=113$ & $\mathrm{~N}=7$ \\
Distoangular & 13 & $10.83 \%$ & 12 & 1 \\
Mesioangular & 71 & $59.17 \%$ & 65 & 6 \\
Horizontal & 15 & $12.5 \%$ & 15 & 0 \\
Vertical & 21 & $17.5 \%$ & 21 & 0 \\
\hline
\end{tabular}

Of the 120 impactions, $43(35.83 \%)$ were soft tissue impactions and 77 (64.16\%) were bony impactions. Out of a total of 7 cases of nerve damage, 6 were associated with bony impactions and 1 case with soft tissue impaction.

As the impactions can be superficial and deep, so their frequency and complications related to IAN are given in table 2 .

Table 2. Depth of tooth.

\begin{tabular}{llll}
\hline & & No Nerve Injury & Nerve Injury \\
\hline Depth & $\mathrm{N}=120$ & $\mathrm{~N}=113$ & $\mathrm{NN}=7$ \\
Moderate & 39 & 34 & 5 \\
Superficial & 81 & 79 & 2 \\
\hline
\end{tabular}

63 patients experienced pain during luxation of the tooth while 57 patients did not. 6 cases suffered pain during luxation of the tooth and one with no pain at luxation were associated with inferior alveolar nerve damage.

17 cases of the mandibular third molars were with grooved roots and in 103 cases there was no grooving present. Damage to the inferior alveolar nerve was seen in 5 cases of 17 teeth with grooved roots and in 2 cases of teeth without groove on root/s.

The various radiographic signs appearance and surgical 
findings suggestive of nerve damage are shown in table 3.

Table 3. Radiographic sign appearance and Nerve injury.

\begin{tabular}{|c|c|c|c|c|c|}
\hline & & Surgical Finding & & No Nerve Injury & Nerve Injury \\
\hline Radiographic Signs & $\mathrm{N}=120$ & Profuse Bleeding & Visualization of Neurovascular Bundle & $\mathrm{N}=113$ & $\mathrm{~N}=7$ \\
\hline 1 Superimposition & 17 & 1 & 2 & 16 & 1 \\
\hline 2 Increased Radiolucency & 38 & 5 & 21 & 37 & 1 \\
\hline 3 Deflection of roots & 5 & 3 & 4 & 2 & 3 \\
\hline 4 Interruption of the radiopaque border of IAC & 31 & 1 & 4 & 31 & 0 \\
\hline 5 Diversion of IAC & 4 & 1 & 3 & 3 & 1 \\
\hline 6 Narrowing of IAC & 25 & 2 & 4 & 24 & 1 \\
\hline
\end{tabular}

\section{Discussion}

The removal of impacted mandibular third molar (M3) is one of the most common procedures in oral surgery. Neurosensory dysfunction of iatrogenic origin is the most distressing sequel to this procedure. The incidence of this complication ranges from $0.5 \%$ to $5.3 \%$, third most common after alveolar osteitis and post-operative infections.

In this study, the relationship of mandibular third molar and inferior alveolar nerve proximity based on OPG was seen. The Mesioangular impactions were seen in $71(63 \%)$ of cases, Distoangular impactions were seen in $13(10.83 \%)$ of cases, Horizontal impactions were seen in $15(12.5 \%)$ of cases, Vertical impactions were seen in $21(17.5 \%)$ while I another study conducted by Mevlut Celikoglu et al the mesioangular impaction was $77.4 \%$, distoangular $8.7 \%$, horizontal in $13.4 \%$ and vertical in $8.7 \%$ of the cases [11].

From overall 120 patients, there were $43(35.83 \%)$ soft tissue impactions, and only 1 case with nerve damage was seen during extraction while $77(64.16 \%)$ of hard tissue impactions there were 6 cases of nerve damage which is accredited with the study conducted by Ishfaq $\mathrm{M}$ et al that there are higher chances of nerve damage in full bony impactions as compared to those that are only soft tissue impactions [12].

As the impactions can be superficial and deep too, so in this study, there were 39 cases with moderate depth and 5 cases of them were with nerve damage was seen. On the other hand, 2 cases of nerve damage were seen during the extraction of total 81 cases of soft tissue impactions. This is favored by the study conducted by Rafael Sarikov et al who said that there are more chances of nerve damage during removal of bony impactions of mandibular third molar [13].

Of all the participants 63 cases experienced pain during luxation and 6 of them were associated with nerve damage while the remaining 57 didn't experience any pain and only 1 case from it was associated with nerve damage which is also mentioned in the study conducted by Gerardo La Monaca et al [14].

Another fascinating result in this study is that out of total 17 grooved roots of mandibular third molar there were 5 cases of nerve damage while on the other hand out of a total of 103 cases where no root grooving was present and from them, only 2 was associated with nerve damage. This is in agreement with the study conducted by Gerardo La Monaca et al that there are greater chances of nerve damage and stretching during the extraction of mandibular $3 \mathrm{M}$ with curved roots [14].

Radiographs are mandatory during the extraction of $3 \mathrm{M}$, so Orthopantomagram is recommended to interpret the various structures that may complicate the procedures. In this study that various radiographic signs were noted before the extraction of mandibular $3 \mathrm{M}$. on evaluating the radiographs, there was a superimposition of structures in 17 cases and one of them was related to nerve damage. There was increased radiolucency in 38 cases and only 1 case from them was associated with nerve damage. Deflection of roots in 5 cases was also seen on radiographs and 3 of them complained about symptoms of nerve damage. Diversion and narrowing of IAC were seen in 4 and 25 cases respectively but only 1 case from each of them was associated with nerve damage. Out of all the 120 cases, 8 cases presented to us with more than 2 radiographic signs, and 5 cases of them were associated with nerve damage. These radiographic results are vowed in the study conducted by Rafael Sarikov et al who showed that there are greater chances of nerve damage when the following features are seen on radiographs, root deflection, superimposition of structures, increased radiolucency, diversion, and narrowing of IAC [15].

\section{Conclusion}

Within the limits of this study, we concluded that there are greater chances of inferior alveolar nerve damage during the extraction of mandibular 3M (impacted or Non-Impacted) when there is root grooving/ deflection, superimposition of structures on radiographs, increased radiolucency, diversion and narrowing of IAC. The chances to nerve damage also increase significantly when there is more than one radiographic sign present and the tooth is deeply placed in the mandible nearest to the IAN. The chances to nerve damage also increases significantly during aggressive instrumentation. It was also noted that when there is vein or artery raptured and bleeding is pulsatile, stop that bleeding gently and avoid aggressive instrumentation, this in turn also reduces the chances of nerve damage.

\section{Conflict of Interest}

All the authors do not have any possible conflicts of interest. 


\section{References}

[1] Leung YY, Cheung LK. Risk factors of neurosensory deficits in lower third molar surgery: a literature review of prospective studies. Int J Oral Maxillofac Surg. 2011; 40: 1-10.

[2] Kjølle GK, Bjørnland T. Low risk of neurosensory dysfunction after mandibular third molar surgery in patients less than 30 years of age. A prospective study following removal of 1220 mandibular third molars. Oral Surgery, Oral Medicine, Oral Pathology and Oral Radiology. 2013; 116 (4), 411-417. doi: 10.1016/j.0ooo.2013.06.024.

[3] Blondeau F, Daniel NG. Extraction of impacted mandibular third molars: postoperative complications and their risk factors. J Can Dent Assoc. 2007; 73: 325.

[4] Genù PR, Vasconcelos BCE. Influence of the tooth section technique in alveolar nerve damage after surgery of impacted lower third molars. Int J Oral Maxillofac Surg. 2008; 37: $923-$ 928.

[5] Szalma J, Lempel E, Jeges S, Szabó G, Olasz L. The prognostic value of panoramic radiography of inferior alveolar nerve damage after mandibular third molar removal: a retrospective study of 400 cases. Oral Surg Oral Med Oral Pathol Oral Radiol Endod. 2010; 109: 294-302.

[6] Jerjes W, Upile T, Shah P, Nhembe F, Gudka D, Kafas P, et al. Risk factors associated with injury to the inferior alveolar and lingual nerves following third molar surgery revisited. Oral Surg Oral Med Oral Pathol Oral Radiol Endod. 2010; 109: 335-345.

[7] Flygare L, Öhman A. Preoperative imaging procedures for lower wisdom teeth removal. Clin Oral Investig. 2008; 12: 291-302.

[8] Palma-Carrio C, Garcia-Mira B, Larrazabal-Moron C,
Penarrocha-Diago M. Radiographic signs associated with inferior alveolar nerve damage following lower third molar extraction. Med Oral Patol Oral Cir Bucal. 2010; 15: 886-890.

[9] Céspedes-Sánchez JM, Ayuso-Montero R, Marí-Roig A, Arranz-Obispo C, López-López J. The importance of a good evaluation in order to prevent oral nerve injuries: a review. Acta Odontol Scand. 2014; 72: 161-167.

[10] Valmaseda-Castellon E, Berini Aytès L, Gay-Escoda C. Inferior alveolar nerve damage after lower third molar surgical extraction: a prospective study of 1117 surgical extraction. Oral Surg Oral Med Oral Pathol Oral Radiol Endod. 2001; 92: 377-383.

[11] Celikoglu, M., Miloglu, O., \& Kazanci, F. Frequency of Agenesis, Impaction, Angulation, and Related Pathologic Changes of Third Molar Teeth in Orthodontic Patients. Journal of Oral and Maxillofacial Surgery, 2009; 68 (5), 990-995. doi: 10.1016/j.joms.2009.07.063.

[12] Ishfaq M, Wahid A, Rahim AU, Munim A. Patterns and presentations of impacted mandibular third molars subjected to removal at khyber college of dentistry peshawar. Pakistan oral \& dent. Jr. 26 (2) dec. 2006.

[13] Sarikov R, Juodzbalys G. Inferior alveolar nerve injury after mandibular third molar extraction: a literature review. J Oral Maxillofac Res. 2014; 5 (4): e1. Published 2014 Dec 29. doi: 10.5037/jomr.2014.5401.

[14] La Monaca G, Vozza I, Giardino R, Annibali S, Pranno N, Cristalli MP. Prevention of neurological injuries during mandibular third molar surgery: technical notes. Ann Stomatol (Roma). 2017; 8 (2): 45-52. Published 2017 Nov 8. doi: 10.11138/ads/2017.8.2.053.

[15] Loescher, A. R., Smith, K. G., \& Robinson, P. P. Nerve Damage and Third Molar Removal. Dental Update. 2003; 30 (7): 375-382. doi: 10.12968/denu.2003.30.7.375. 